IRSH 49 (2004), pp. $225-247$ DOI: I0.1017/S002085900400I 506

(C) 2004 Internationaal Instituut voor Sociale Geschiedenis

\title{
Jewish or Arab Hired Workers? Inner Tensions in a Jewish Settlement in Pre-state Israel
}

\author{
YAIR SELTENREICH
}

\begin{abstract}
Summary: The agricultural settlement was essential in the process of establishing the state of Israel. In the I92os the Zionist leadership claimed exclusivity in employing Hebrew workers. This research focuses on the lone Moshava settlement, and examines the reasons why its farmers, opposing the hegemonic ethos, preferred the employment of Arab workers. In the broader historical context, this article's interest is the possible reactions of a peripheral social group straining under the pressure of the hegemonic elite. The research shows how the farmers' position caused increasing involvement by powerful external organizations in the decisionmaking process of employment, to such an extent that the farmers virtually lost their control of the matter. Furthermore, the research illustrates how the fact that national institutions and the Hebrew workers belonging to the same ideological environment caused social values to be identified with national values and favoured them over economic values.
\end{abstract}

\section{INTRODUCTION}

Agricultural settlements played a central role in the establishment of the Jewish state. The first wave of immigration (aliyab), which began in the late nineteenth century, settled primarily in rural settlement called moshavot (singular - moshava). In most of the moshavot, the farmers were supported by philanthropic organizations with the expectation that they would eventually become self-sufficient producers. The farmers wished to become self-sufficient for the additional reason of freeing themselves from the influence of the philanthropic organizations. The next two waves of aliyah, the first at the turn of the century and the second following World War I, were primarily composed of young people imbued with socialist ideals. As a result of the economic depression, they developed an ambivalent attitude towards the moshavot farmers. On the one hand, they were in need of them as employers but on the other hand viewed them ideologically as an enemy class. The dominance of political institutions by the labour movement, beginning in the I920s, gave them organizational and ideological support and pushed the moshavot to the margins. 
The confrontation between the local Arab population and the Jewish immigrants was inevitable. The Arabs living near the moshavot found employment there, and the farmers viewed the Arabs as a source of cheap, disciplined, and skilled labour. At the same time, each group had its own interests which clashed on both the local and national levels. In most cases, Arabs and Jews did not understand each other, nor were they willing to make an effort to do so. During the first half of the twentieth century, conflicts over the control of resources developed into bloody confrontations. Over time, the conflict took on symbolic meanings and a more national character.

The encounters between the moshavot farmers and the Arab workers on the one hand, and between the moshavot farmers and the Jewish (or "Hebrew" as they called themselves) workers on the other, were particularly complicated as they reflected both the mutual needs of each group and the tension between them as a result of opposing views. These relations became intertwined when, in the I920s, the Zionist leadership adopted the principle of Hebrew labour. This principle called for the exclusive employment of Hebrew workers, for nationalistic reasons and in order to provide employment for new immigrants. However, economic reality made it impossible to implement fully the principle of Hebrew labour. This economic reality dictated a different agenda for the farmers, which led to tension between them and the Hebrew workers. It can be assumed that these tensions were more acute in the periphery where the conflict was more pronounced and the national political institutions had less influence. It is this area which has largely been ignored by researchers.

The corpus of research deals with the Hebrew labour question, most of which focuses on the Hebrew workers, since they became the dynamic force within the Jewish society. Moreover, most of the research deals with the elite of the workers' society, emphasizing organizational, political, or moral aspects. A prime example is the book by Anita Shapira, ${ }^{\mathrm{I}}$ which examines the role of Hebrew work in shaping the ideology of the Hebrew working class during the 1930s. Shapira presents the farmers only in order to clarify that point, mainly concerning their political role. Among later works we should mention that of Nahum Karlinsky on the role of Hebrew citrus workers, and that of David De Vries, who examines the special role of "Red" Haifa as a workers' town. ${ }^{2}$ Through the prism of social history,

I. Anita Shapira, Hamaavak Hanichzav. Avoda Ivrit, 1929-1939 [Futile Struggle: The Jewish Labour Controversy, 1929-1939] (Tel Aviv, 1977) (Hebrew).

2. Nahum Karlinsky, Prikhat heHadar. Yazamut Pratit baYishuv, 1890-1939 [Citrus Blossoms: Private Enterprise and the Jewish Citrus Industry in Palestine, I895-1939] (Jerusalem, 200I) (Hebrew); David De Vries, Idealism uBiurokratia biShnot haEsrim. Poaley Haifa bitnuat haAvoda haEretz-israelit, 1918-1930 [Idealism and Bureaucracy in 1920 P Palestine: The Origins of "Red Haifa"] (Tel Aviv, 1999) (Hebrew). 
De Vries attempts to understand how and why the workers' movement became powerful, both politically and socially. He analyses the relationship between social phenomena and organizational processes, or between economic ideas and national practices. Although De Vries studies a local environment, it is an urban, and not an agrarian one.

Studies on the moshavot, such as those by Yossi Ben-Artzi and Ran Aaronson, focus on geographical and organizational aspects rather than social ones, and barely deal with social questions in general and those of labour relations in particular. Amir Ben-Porat considers the formation of the Jewish working class as a particular case, which should not be explained merely by a model of class formation, since it was incorporated also into a process of nation-building. Since agriculture was, at that period, the major source of employment, frictions between workers and farmers developed mainly in the moshavot. Gershon Shafir conceives the settlement process as based mainly upon attempts to gain control of land and the labour market, and gives a minor role either to ideologies or to intra-Jewish political conflicts. In a recent article, Yosef Gorni compares the sociomental profile of both Jewish social groups, farmers, and Hebrew workers. He emphasizes the disappointment caused by their common encounter, with the Hebrew work as a bone of contention, impregnated with pragmatic, moral, and national feelings. But Gorni deals with an earlier period, preceding $1917 .{ }^{3}$

Some works focus on the Arab labour question. Ya'akov Ro'I presents the attitude of the farmers in the centre of Palestine towards the Arabs, patronizing and full of suspicion, fed with nationalistic and political concepts. Deborah Bernstein and Zacharia Lockman ${ }^{4}$ deal with urban rather than with rural contacts between Arab and Hebrew workers. Furthermore, they deal mainly with organizational questions.

3. Yossi Ben-Artzi, Hamoshava halvrit beNof Eretz-Israel, I882-19I4 [Jewish Moshava Settlement in Eretz-Israel, I882-1914] (Jerusalem, I988) (Hebrew); Ran Aaronson, Habaron veHamoshavot. Hahityashvut haYehudit beEretz-Israel bereshita, I882-I 890 [Baron Rothschild and the Colonies: The Beginnings of Jewish Colonization in Eretz Israel - I882-I890] (Jerusalem, 1990) (Hebrew); Amir Ben-Porat, Between Class and Nation: The Formation of the Jewish Working Class in the Period Before Israel's Statehood (New York, I986); Gershon Shafir, Land, Labor and the Origins of the Israeli-Palestinian Conflict, I882-I9I4 (New York, I989); Yosef. Gorni, "Hayishuv heKhadash, I882-1917" ["The New Immigrants, I882-1917"], in Moshe Lissak and Israel Kollat (eds), Toldot haYishuv haYebudi beEretz-Israel me'az haAliah haRishona. Hatkufa haOtmanit [The History of the Jewish Community in Eretz-Israel since I882, The Ottoman Period] (Jerusalem, 2002) (Hebrew), vol. 2, pp. 4I 5-456.

4. Ya'akov Ro'i, "Yahasey Yehudim-Arvim Bemoshvot Ha'aliah Harishona” ["Arab-Jews Relationship in First-Aliah Settlements"], in Mordechai Eliav (ed.), Sefer Ha'aliah Harishona, [The First-Aliah Book] (Jerusalem, I982) (Hebrew), vol. I, pp. 245-268. Deborah S. Bernstein, Constructing Boundaries: Jewish and Arab Workers in Mandatory Palestine (Albany, NY, 2000); Zachary Lockman, Comrades and Enemies: Jewish and Arab Workers in Palestine, 1906-1948 (Berkeley, CA, I996). 
Unlike the research mentioned above, this article will not examine the Hebrew work problem either from the workers' point of view, or from that of elite groups. It will therefore focus on the narrative of ordinary farmers and their conceptual approach to the problem, a conception that gave precedence to daily pragmatic necessities over organizational, political, or moral aspects. This article examines the attitudes of farmers in their choice between employing Jewish or Arab labour. It will look at the changes in the farmers' degree of control over the decision-making process, whether these changes were a result of employer-employee relations or the influence of external pressure groups, and finally consider how farmers reacted to this pressure.

It should be emphasized that the contribution of this article is not only to the specific domain of its case study; it also raises a question in a broader historical context, concerning the ability of a peripheral social group to react to pressure from a hegemonic elite. The historical applications might be analysed, for instance, by trying to understand the relative weight given at the time by different participants to values or to political forces. Such an explanation can help understand their belated reactions. It may also be added that such situations, of pressure from the elites, occur more frequently in immigration countries, where pressure originates from the fact that new peripheral groups are 'added' to existing society. Nevertheless, in order to clarify the picture, this research studies a single moshava as a test case. As we shall see, when we come to investigate a peripheral environment, we might find numerous, more perspicuous sources on the local level. A study in local history enables us to understand more accurately the different events and derive more refined presumptions and questions which, in their turn, would be recirculated into the macro level.

The region to be studied is the Lower Galilee, a rural area in northeastern Palestine. This region was relatively isolated from the political and cultural centres in Palestine and was characterized by neighbourly relations between Arabs and Jews. Arab society was heterogeneous and its population included both agricultural and nomadic components. The Jewish population in the region lived primarily on moshavot. The arrival of Jewish immigrants in the region was only one small part of a massive and heterogeneous wave of immigration. Beginning in the mid-nineteenth century, the Ottoman authorities had encouraged the migration of Mughrebin from North Africa, Circassians from the Caucasus, Egyptians, and others to the Lower Galilee. To these were added Bedouins from Trans-Jordan. Jewish immigration, which began arriving in the region in I90I, settled on about 8,000 hectares of land which had been purchased by the Jewish Colonization Association (the JCA), a philanthropic society created and financed by the French Jewish millionaire, Baron Hirsch, in order to encourage Jewish agricultural settlement. Until then the JCA functioned mainly in Argentina (the JCA 


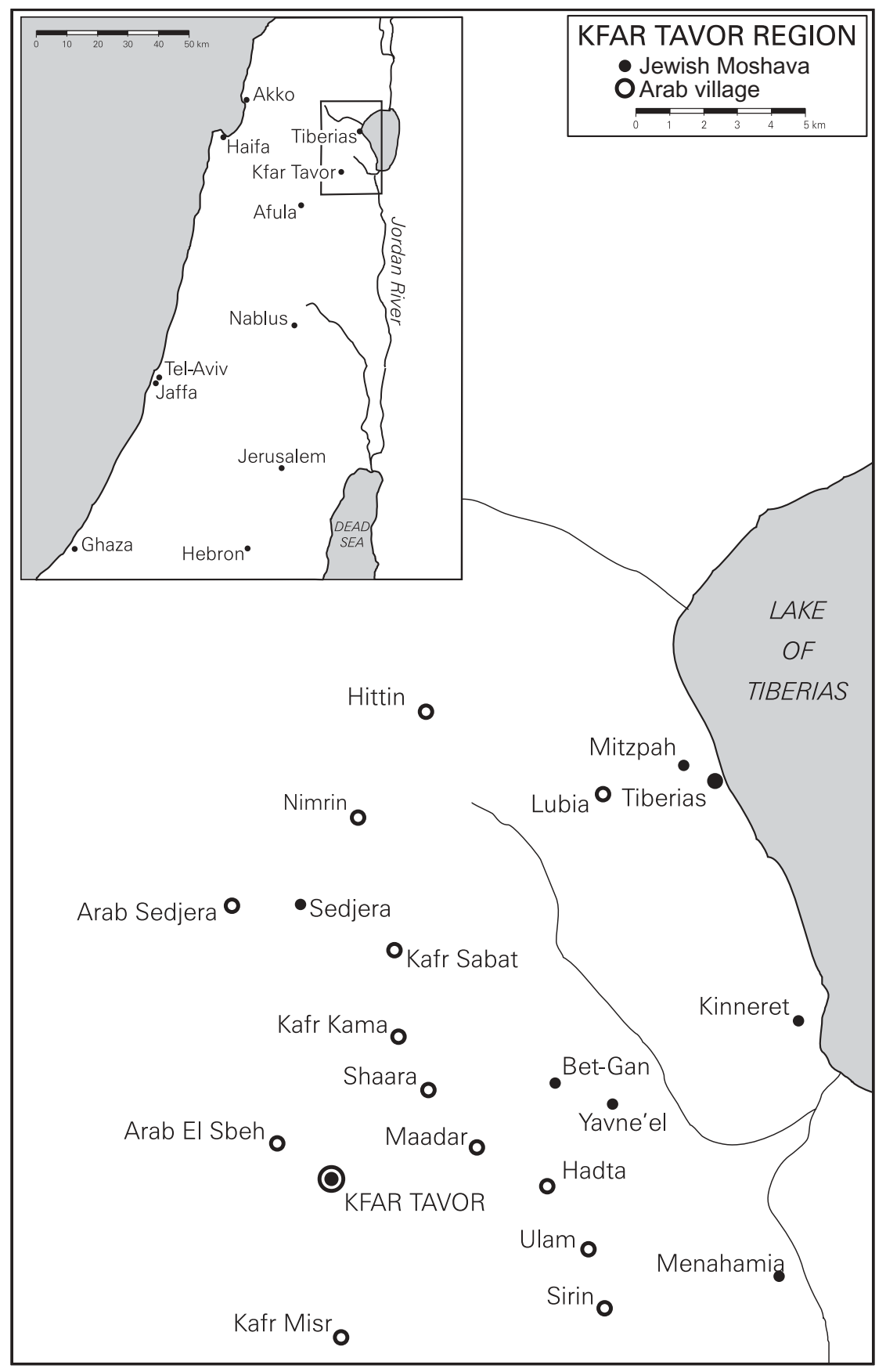

Figure I. Lower Galilee 
was known as the PJCA from 1924 on). The JCA settled less than I,०00 immigrants on four moshavot. 5

This article concentrates on one typical moshava, Kfar Tavor, which included 37 farmers and a total population of 250 . The history of this moshava is particularly well documented. The various attitudes prevalent in that period are reflected in the protocols of the general meetings of local farmers and the weekly committee meetings. These protocols are kept in the Kfar Tavor archives. Other sources include the protocols of meetings of the Lower Galilee Farmers' Association (hereafter the LGFA). This organization was formed during World War I in order to facilitate the social and economic activities in the moshavot of the region, but it quickly developed a rather authoritarian character, representing, in fact, only a minor but powerful section of farmers. Its protocols were hidden for decades by one of its members and given to me recently by his son.

\section{LABOUR RELATIONS UP UNTIL THE I $920 \mathrm{~S}$}

The constant economic crisis among farmers in Lower Galilee made the struggle for existence their most pressing issue. As often happened in pioneering environments, reality made poverty tangible, and generated anxiety which surmounted idealistic aims. Although Jewish and Arab farmers had different economic structures and utilized different agricultural techniques, all farmers faced the same basic problem: cultivation in a relatively dry environment, with unstable precipitation and no existing irrigation system. Many small Arab farmers had given up years before and had sold their land to rich effendi. They continued to till the land as harratin (singular harrat), tenant farmers, in return for 20 per cent of the yield.

Each Hebrew farmer was allocated an unusually large area of 25 hectares by the JCA which was calculated (wrongly as it turned out) to be sufficient to sustain a family under the local agricultural conditions. It quickly became clear that an individual farmer was unable to cultivate such a large area on his own. On the other hand, if he used hired workers, then labour costs became a critical component in his budget. A farmer who found himself in financial straits would seek to reduce costs. He considered hired labour to be both a necessity and a heavy financial burden. Thus he faced two options: either hire a harrat, an Arab worker who would help him in exchange for 20 per cent of the annual yield, or hire a Hebrew worker who was less efficient and more costly. Under these conditions, contact

5. See for details: Arieh Bitan, Tmurot Yishuviot baGalil haTakhton haMizrakhi: (1800-1978) [Changes of Settlement in the Eastern Lower Galilee (1800-1978)] (Jerusalem, I982) (Hebrew), pp. 27-96; David Grossman, Hakfar haArvi Uvnotav. Tahalichim baYishuv haArvi beEretzIsrael baTkufa haOtmanit [Expansion and Desertion: The Arab Village and its Offshoots in Ottoman Palestine] (Jerusalem, I994) (Hebrew), pp. 3-57 and 79-I0I. 
between Hebrew employers and Arab workers was inevitable. Within a few years, most of the farmers in Kfar Tavor had harratin living on their farms. Arab society could not offer those harratin the same levels of income, economic security, and living conditions. Therefore, the Arab workers had an interest in maintaining their places of work. The farmers, who could not have found better workers, also had an interest in maintaining the status quo.

At the same time, tension existed between the farmers and the Arabs. Although the farmers learnt Arabic and respected many of the Arabs' social codes, such as bakshish (a Turkish term for bribery) and sulha (for ending a blood feud), cultural differences increased the tension. Thus, for example, the Bedouin regarded theft as legitimate and considered unguarded agricultural produce or uncultivated land to be ownerless. The Hebrew farmers bitterly opposed this approach. The tension between the two groups was the result of an ongoing series of individual incidents. Nationalistic sentiments found expression among farmers in their feeling that they were pioneers bringing the land of their Biblical forefathers back to life. The main motif within this vision was a return to the land, which was devoid of political or militaristic meaning. Among rural Arabs we find practically no nationalistic sentiment during the I920s and even later. Nevertheless, the two groups already felt contempt for one another.

Hebrew workers arrived in the Lower Galilee during the same period as Hebrew farmers. Unlike the farmers, who were in their forties and had families, the workers were young and unmarried. Both farmer and the worker had come to build the national homeland, but each had his own view of how this was to be accomplished: the farmer favoured a capitalistic approach while the worker believed in socialism. Nevertheless, during the early years, farmers and Hebrew workers still shared a common sense of destiny. They shared a feeling of attachment to Galilee, a region which was viewed differently from other parts of the country, and was considered to be a "wild and inhospitable land". ${ }^{6}$ This, together with their shared poverty and love of agriculture, intensified the feelings of unity between them. "The worker lives, works and eats with the farmer. Making a distinction between the worker and the farmer is an insult to the farmer." Both believed that their hardships were only temporary and would soon pass.

Attitudes changed, however, during World War I, when income levels fell to below subsistence levels and farmers experienced the trauma of not being able to feed their families properly. This intensified the effort to

6. Shaul Dagan (ed.), Rishonim beUm Djuni: haAvramsonim [Pioneers in Um-Djuni: The Avramsons] (Afula, I986) (Hebrew), p. 26.

7. Aaron Ever-Hadani, Hahityashout baGalil haTachton. Hamishim Shnot Koroteha [The Settlement in Lower Galilee: Jubilee Book] (Ramat-Gan, 1956) (Hebrew), p. 207. 
protect meagre sources of income. Following the war, labour relations on the Lower Galilee moshavot entered a new phase, which was characterized by tension between farmers and the national Jewish leadership, who were more closely identified with workers than with farmers. The leadership's national values, including the principle of employing Hebrew labour, differed in emphasis from those of the farmers. From that point on, the employment of agricultural workers ceased to be a solely economic issue and became an ideological one as well. The national leadership could hardly have adopted a pluralistic attitude to the issue during that period. Not only did it oppose the employment of Arab labour, it even opposed the employment of the farmers' own sons, who were not workers in the political and ideological sense. "Farmers claim the jobs are theirs $[\ldots]$ and they are eager for their sons to learn the work too." ${ }^{\prime}$ The result was increasing tension between farmers and Hebrew workers.

Jewish organizations showed a lack of sensitivity to farmers, and farmers in turn took a similar attitude towards Hebrew workers. Farmers considered them to be unskilled, and showed no appreciation of their difficulties as new immigrants in adjusting to new labour relations and difficult climatic conditions. Farmers believed the intense ideological discussions held by the workers to be a waste of time. The educator, Israel Weinberg, expressed this feeling in The Tickler, a satirical magazine: "We worked for the farmers on the moshavot. We were reluctant to work too hard, lest they earn too much on our account. Thus, we learned to be lazy." "As for collectivism, the farmer did not appreciate the sacrifice and loyalty it required, but rather viewed it as an opportunity for licentiousness and the neglect of religious duties. Thus, we find the following ad in the satirical newspaper The Carob, published in Metullah: "Wanted: Worker. Conditions: No running around with young girls; lights out at seven in the winter and at nine in the summer." ${ }^{\circ}$ The farmers also felt that the workers were insensitive to their problems. This can be seen in the words of one farmer, Nahman Karniel: "I remember once when I had no money with which to pay the salaries of my Hebrew worker. He would not accept my apology and was even prepared to sue me." Another, Joseph Buchbinder, said that he was "prepared to use Hebrew labour, on condition that the workers use their own kitchen because the farmer is prepared to miss a meal once in a while, while the worker is not". ${ }^{\text {II }}$

8. Yehuda Antebi diaries [hereafter, Antebi], January I924, private collection, by courtesy of Ms Zohara Antebi.

9. The Tickler, n.d. (before I9I4), private collection, fo. 24 .

I0. I9I 5, The Lavon Research Institute of Labor Movement [hereafter, Lavon], Tel Aviv, series 4,235 II 285 .

I I. February i93 I, Kfar Tavor Archives [hereafter KTA], series 39-3, protocol 84; November I929, KTA, ibid., protocol 28. 
There also existed a great deal of ideological tension. Many of the newer workers, who had arrived after World War I, came from Russia and therefore had witnessed the October Revolution first-hand and were more ideologically impassioned than their predecessors. Over time, their numbers grew and their organizations became more efficient. While the farmers were supported by the JCA, a private society, the workers enjoyed the support of national organizations. On the ideological level, the workers came to view themselves more and more as symbolizing the "right" way. Their views were shared by part of the establishment (political parties and settlement organizations). In Kfar Tavor, farmers feared that their economic position would become undermined and that their children would be attracted by the collectivist idea and leave the moshava. This fear is expressed in the diary of a local schoolmaster, Yehuda Antebi, who writes: "There were discussions between myself and the servant which made me very angry. This is the problem between workers and their employers. Now it is the employers who are supposed to take the orders. There is a Bolshevik wind blowing and nowhere to hide from it." I2 Another example is that of Tova, the daughter of a farmer, Zalmen Ashbel. Ashbel was formerly a wealthy farmer in Hadera, but due to climatic conditions, Tova had fallen ill there twice with yellow fever "and therefore he had left Hadera, ruining himself financially. Disregarding his prospects in Hadera, he moved in order to protect his daughter from the threat of fever." Now Tova wanted to leave home to join the collective group organizing in Kfar Tavor. The moshava committee warned the group not to take Tova with them to their planned site in Migdal where a danger of yellow fever existed. They were warned that if they did so, they would be held responsible for her health. ${ }^{13}$

Economic events during the 1920 s fuelled the situation. In 1924, there was an upsurge in the demand for tobacco. The demand for Hebrew workers, in addition to the existing demand for Arab workers, soared. During the peak year of I924, more than I,000 Hebrew workers, more than the entire population of the moshavot, were living in the region. The sudden collapse of the tobacco industry in 1926 caused an unprecedented wave of unemployment which considerably worsened relations between farmers and workers.

\section{FARMERS'PERCEPTION OF THE WORKERS}

By the end of the I920s, we can point to a common perception among the farmers of Jewish and Arab workers. We can divide this perception into five components.

I2. January 1930, Antebi.

I3. Kfar Tavor Committee to Migdal Committee, [1927], KTA, series 35-2, file 36. 


\section{Continuity}

Although the contract between the farmer and the harrat was renewed on an annual basis, in reality it was understood as a long-term relationship which implied a sense of mutual responsibility. Indeed, many of these relationships lasted for decades, until they were ended as a result of external pressures. Local records hardly mention any real tension between farmers and harratin. On the other hand, the relationship between the farmer and the Hebrew worker was more functional in character. Usually, the contract was signed between a farmer and a group of workers rather than with individual workers, thus reducing the personal aspect of labour relations. The Hebrew workers felt more committed to labour values or to their collective than to the moshava. Some workers aspired to becoming independent farmers themselves, which prevented the creation of a real bond with their employer.

\section{Terms of employment}

The contractual arrangement of the Hebrew worker was totally unlike that of the Arab worker. The Hebrew worker's obligations were limited to agricultural services. He was paid a fixed salary, which was independent of his employer's revenue. In contrast, the harrat was employed together with his family, and they were expected to provide domestic as well as agricultural services. Compensation was paid to the family as a unit and was calculated as a fixed percentage of the yield. Success, therefore, was in the interest of both the farmer and the harrat, which strengthened the ties between them.

\section{Attitude towards work}

Here, too, there was a basic difference between the Hebrew and Arab worker. For the harrat, agriculture was a way of life. For the Hebrew worker, work was a value and a matter of choice, and could be used as a lever for the improvement of society. The Hebrew worker thus felt the right to criticize the farmer's way of life, and considered the farmer to be a capitalist exploiter rather than his provider. Such an attitude was impossible for the harrat whose economic fate was tied to that of the farmer. He viewed the farmer as his ally. Clearly the daily encounter with the harrat was less tense for the farmers than the encounter with the Hebrew worker.

\section{Security}

Although there were violent encounters between Jews and Arabs during the period beginning in I90I, violent incidents between Jews and harratin were rare. We find no records of robberies, physical attacks or cooperation 
with hostile elements outside the moshava, and only a few recorded cases of petty theft and disagreements about contracts. Thus, the harratin did not represent a security threat, at least until the Arab Revolt against the Mandate authorities (1936-1939). During periods of increased tension, the movement of the harratin within the moshava was restricted, but only as a measure to increase security. For example, during the "May I920 Disturbances" (Jewish reference to the bloody clashes between Arabs and Jews erupting that year throughout Palestine), it was feared that Arabs would raid the moshava, although we find no record of harratin presenting a security problem. However, the harratin did have to leave Kfar Tavor for a while during that period. ${ }^{14}$ Did the Hebrew workers contribute to the level of security? The Jewish authorities viewed them as additional defenders for the moshavot although the farmers claimed that they had little value as guards. The farmers even claimed that, during periods of tension, they had to supply guards for the Hebrew workers in the fields, which added to their financial burdens.

\section{Nationalistic sentiments}

The harratin, unlike Arabs in the cities, had not developed nationalistic feelings. They had little contact with nationalistic elements (through newspapers, political gatherings, etc.) nor were they prepared to give any priority to the needs of Palestinian Arabs as a national group. As for the Hebrew workers, while holding the same Zionist goals as the farmers they had basic disagreements over the character of the future Jewish state. In particular, they disagreed over the right of the government to intervene in economic matters (in this case, the obligation of employing Hebrew labour), and over the designation of land bought with public funds.

We see then that tensions tended to appear more frequently in relations with Hebrew workers, as the farmers were accused of giving priority to the problems in their immediate environment rather than those on the national level. We shall return to this point, which bears a more general historical significance, when the political weakening of a certain social group is related to the insinuation that it is less faithful to national values, as they are understood by an ascending group.

\section{THE NEW PRODUCTION SYSTEM}

At the end of the I920s, the economic situation of the farmers on the moshavot was no better, and perhaps even worse, than it had been thirty 
years earlier. Their income was meagre and unpredictable; they were unable to keep their sons on the moshava; and they were locked into a complex dependence on hired labour. The LGFA understood that unless a radical solution was found, the moshavot would collapse. Furthermore, economic success would serve the interests of both the LGFA and PJCA. It would strengthen the LGFA's political position at national level and prevent the loss of investments made by the PJCA during the previous decades. LGFA therefore planned to implement a new system of agricultural production and was prepared to coerce the farmers into accepting it. The new system involved the collectivization of all land on a moshava and its cultivation according to centralized planning. The system would improve yields, and as a consequence would free up part of the land for new settlers.

At the same time, there was apprehension about the plan. It bore economic risks and entailed mechanization, which would require the employment of more costly Hebrew workers. In other words, the introduction of the new system made the Hebrew worker a necessity. For the first time, the national organizations explicitly demanded the exclusive employment of Hebrew labour. Most farmers in Kfar Tavor were opposed to the introduction of the new system. Decades of economic difficulty had reinforced their conservative attitudes. They felt that their dependence on the PJCA left them no real control over their affairs, and therefore they tried desperately to preserve what was left of their independence. They were suspicious of even their own moshava committee. ${ }^{\text {Is }}$ They believed that the new system, and the accompanying necessity of employing Hebrew workers, would lead to the direct control of farming by the LGFA in cooperation with the workers' organizations, such as the Galilee Workers' Organization.

The concept of Hebrew labour took on new significance from this point on: it became a symbol of new ideas, such as the right to intervene in economic matters, and it received far more weight in public discourse. Thus, the argument between the farmers and the LGFA was transformed into a debate over the place of Hebrew labour on the moshava. This resulted in two significant changes in labour relations. First, the discussion was no longer between the farmers and the workers but between the farmers and the organization representing them, i.e. the LGFA and, to a lesser extent, the PJCA. This led to a reduction in the farmers' power. Second, there was a shift in the focus of discussion from the "worker" to the "work" or, in other words, from the level of the individual to the level

I 5. Yair Seltenreich and Orit Manor, "Asefa, Vaad Umuchtar biKfar Tavor. Mikre Heker Behistoria Hevratit" ["Assembly, Committee and Mukhtar in Kfar Tavor: A Case Study in Social History"], Cathedra, 95 (April 2000), pp. 67-100.

I6. September 1929, KTA, series 39-3, protocol 24. 
of the group. The central questions were now related to the normative values of each group. Debate no longer centred around agriculture, but rather involved issues of a broader scope, such as society, security, and nationhood. As a consequence, the problems of the farmer as an employer were marginalized in favour of larger issues. This tactic, in which a specific local problem is transferred to a general arena, be it political or ideological, where power relations change in favour of the more organized elements, and where the game is played according to their rules, is not particular to our case.

The question of Hebrew labour was not new to farmers; however, it now became the dominant issue. In fact, it had already been an issue in 1924, at the height of the tobacco boom. In that year the LGFA emphasized that "our work should be roo per cent Hebrew labour and we should work this out among ourselves". ${ }^{16}$ It also explained to the moshavot "the immense benefits from employing Hebrew labour [...] which may encourage immigration". ${ }^{17}$ Following the collapse of the tobacco sector, the national organizations presented the case for Hebrew labour to farmers in a more practical light, with emphasis on the contribution to security and the economy. At the annual meeting of the LGFA, the following statement was made: "Hebrew labour in all branches of the economy is the main factor through which the economic and security situations in the moshavot will be improved." ${ }^{8}$ The National Committee, the central Zionist institution in Palestine, wrote to Kfar Tavor: "It is clear that in addition to its national value, Hebrew labour has economic value." 19 This letter clearly indicates what the national organizations considered to be the correct hierarchy of values.

\section{THE POSITION OF THE FARMERS}

The introduction of the new system was debated intensively, especially during the period 1929-193I. It was hotly debated in the general meetings of Kfar Tavor farmers. The farmers' arguments were sometimes contradictory and often lacked sophistication, but nonetheless they authentically reflect the farmers' distress and apprehension. They reveal how a population in the periphery, which viewed itself as "under siege", perceived the views of the political and social elites. A farmer, Zalmen Ashbel, mentioned the various objections to Hebrew labour with some irony: one farmer opposed it because "he feared the high cost of Hebrew labour. Another opposed it because of the necessity of feeding the worker.

17. The Palestine Farmers' Association, 26 February I924, Lavon, series 4, 3 I 28 I, fo. 33 .

I 8. 8 December 1924, protocols of LGFA [hereafter LGFA], private collection, by courtesy of Ms Bilha and Mr Ory Scharfman.

19. The National Committee to Kfar Tavor, January 1924, KTA, series 8-2, file 54. 
A third opposed it for no reason at all." ${ }^{20}$ Another farmer maintained that "[the larger moshavot of] Zichron Ya'akov or Petah Tiqva [in central Palestine] are capable of maintaining two kinds of workers [Arabs and Jews] but Kfar Tavor is not." ${ }^{21}$ However, the main argument was based on the conservative attitude of the farmers:

Everyone agrees that Hebrew labour is not relevant. This is a common understanding among the farmers with no need for further explanation [...]. It is human nature not to be progressive. Indeed, in order to force progress on him, he must first be convinced that all new things are good. ${ }^{22}$

Some felt that Hebrew labour was a pretext for compromising the independence of the moshavot: "The assembly cannot force [the individual] to use Hebrew labour", stated a farmer, Reuven Paikiovitz. ${ }^{23}$

Beyond these general arguments, the farmers focused on two aspects of the problem of Hebrew labour. The first was of an economic/demographic character. There was agreement that replacing Arab workers with Hebrew ones would have economic consequences but the sides were split as to how this would affect the local demographic situation. The second involved security and national considerations. It was agreed that national issues had become increasingly urgent as a result of the growing tension between Arabs and Jews. The question was to what extent the situation in Kfar Tavor differed from that in the rest of the country.

\section{Economic/demographic aspects}

The high cost of Hebrew workers worried the farmers. "From what revenue shall we pay them? We are in debt up to our necks." ${ }^{24}$ They believed that if they were forced to hire Hebrew workers exclusively, many farmers would leave the moshava. ${ }^{25}$ In addition, the ageing farmers were finding it difficult to keep their sons on the moshava, and thus to maintain their connection to the region and to their nuclear families. The land allocated to each family was not sufficient to support an extended family. One farmer, David Zfira, complained that "his son has left him to do all the work, saying that there is no future for him there". Another, Benzikovsky, added that "the population in the centre [of Palestine] is steadily growing, while here the younger generation is steadily leaving". ${ }^{26}$

20. September 1929, KTA, series 39-3, protocol 24.

2 I. Without date, Lavon, series 4, 3 I 28 I I 47, fo. I004.

22. 28 January 1934, LGFA.

23. September I929, KTA, series 39-3, protocol 24.

24. March I931, ibid., protocol 84 .

25. November 1929, ibid., protocol 28.

26. February 1931, ibid., protocol 84; io April 1932, ibid., protocol I45. 
Naturally, the farmers viewed the Hebrew workers as potential rivals to their sons, who might in future desire the land for themselves.

The fact that national organizations took only the interests of Hebrew workers into consideration was proof to the farmers that they were deaf to their arguments. The alliance of workers and national organizations was viewed as a real threat to the moshava. The farmers felt that if Hebrew labour was forced on them, then the best solution would be to employ their sons - "self-work", as they called it. Weren't their sons as Hebrew as these workers? The support given to the principle of Hebrew labour by the various national organizations, which was now understood as meaning the exclusive employment of Hebrew labour, proved to the farmers that their real aims were actually political rather than economic, nationalistic, or security-oriented. Farmers opposed the national organizations on this issue, as can be seen in the words of a farmer, Nahman Karniel: "The assembly can decide against Arab labour, but not in favour of Hebrew labour." 27 Another, Yizhak Leibovitz, from the nearby moshava BethGan, declared:

I prefer the revenue from the small threshing floor which I operate on my own to a greater amount of revenue made from a larger operation with a large number of workers who eat up all the revenue. We, who believe in Hebrew self-work, cannot agree to Hebrew labour.

In the end, the general assembly of Kfar Tavor voted to use Hebrew labour although they specified "no outsiders", i.e. no obligation to hire Hebrew workers. ${ }^{28}$

Even those who accepted the principle of Hebrew labour objected to the LGFA's demand that it should be obligatory:

The new system is one thing and Hebrew labour is another; Hebrew labour is only an ideal while the new system will radically affect our lives [...]. We will use [Hebrew labour] as a luxury but not if it ruins us financially. For 75 per cent of the farmers, self-work will be sufficient; the remaining 25 per cent will need workers. The better off farmers will employ Hebrew workers out of idealism and if the rest use cheap [Arab] work, I don't mind. The only thing we should be worried about is our survival. ${ }^{29}$

Zalmen Ashbel tried to strike a balance between the apprehensions of the farmers and the viewpoint of the national organizations: "I believe that the young [the farmers' sons] that know the work will not be displaced if unskilled workers are hired. Those farmers who are too weak to do all the work themselves [...] have the right to hire Arabs in the event that skilled

27. September 1929, ibid., protocol 24.

28. [28 May 1933], LGFA.

29. April i93 I, KTA, series 39-3, protocol 88. 
Hebrew workers are unavailable." $3^{\circ}$ In fact, Ashbel supported the main claim of the farmers that at least some of the Hebrew workers were unskilled and the pressure to hire them at the expense of the farmers' sons originated in moral, rather than professional, considerations. This only reinforced the farmers' belief that control was being taken away from them.

\section{The security/nationalistic aspect}

This involved two questions: First, did the Hebrew workers contribute to the defence of the moshava and second, did the presence of the Arab harratin in the moshava create a danger to its Jewish residents? In either case, the assumption was that defence and security matters took precedence over professional considerations.

Supporters of Arab labour had a great deal of influence in Kfar Tavor. As we have mentioned, there was a belief among the local farmers that the Arabs living on the moshava were harmless; on the contrary, they were even put in charge of security. For example, a contract to guard grain stockpiles was signed between the local committee and two Arabs in 1924. ${ }^{\text {I }}$ A similar contract was signed with Hamud al Hasun in $1928 .{ }^{32}$ Such contracts even existed during periods of tension. For example, on 7 January 1930, the committee was asked to pay for the cost of the forest guard, Mahmud Rashdan, who had been delayed because of the antiJewish riots in 1929. 33 On another occasion, the committee sent an Arab to Trans-Jordan "to retrieve our stolen livestock which had been taken there". ${ }^{34}$ Supporters of Arab labour brought a variety of arguments in their favour. At one general meeting, the farmer, Rothstein, remarked that the farmers who had hired Hebrew workers were reverting back to Arabs. It was believed that expelling the Arabs from the moshava would make them resentful and would lead to reprisals against the moshava. Zalmen Ashel claimed that the presence of the Arabs on their farms had helped to prevent theft at night. ${ }^{35}$

The main counterargument stated that the threat from the Arabs living inside the moshava was made even more serious by their large numbers. "The number of Arab families in the moshava already equals the number of farmers' families. What will happen if that number increases and Kfar Tavor finds itself with ninety [Arab] families as opposed to thirty Jewish ones?" ${ }^{6}$ If Arab workers were replaced by Hebrew ones, the feeling of

30. December I929, ibid., protocol 29.

31. Contract, January I 924, KTA, series $23-4$, fo. 3 .

32. January I928, KTA, series 23-5, file 5.

33. Letter to Kfar Tavor Committee, January 1930, ibid., file I9.

34. September 1922, Zionist Central Archives, Jerusalem, Series J 49 I 5.

35. November 1929, KTA, series 39-3, protocol 29.

36. November 1929, ibid. 
security, would be enhanced. "I employ a Hebrew worker not out of nationalistic ideals [...] but because it contributes to my security." "We have to employ Hebrew labour to protect us because we are totally defenceless." 37

\section{THE POSITION OF THE LGFA}

The objection of the national organizations to Arab labour was based on the values dictated by the national ethos. David Ben Gurion, the national Jewish leader, declared that Arab labour should not be paid from public funds (in 1932 the resources of the PJCA were defined as public funds). He claimed that employing Arab workers did not help to achieve national aims. However, the farmers in Kfar Tavor dealt primarily with the LGFA, whose position was formulated by Haim Zimmerman, its dominant leader. This position was repeated so often that it came to be viewed as no longer open to question. As a result, there came to be a general consensus on the issue and what was previously only assumption was now considered to be fact. Furthermore, it implied that the only solution was to be found within an organizational framework, i.e. the LGFA.

Zimmerman took every opportunity to state the argument that the new system could only succeed with Hebrew labour and that only the introduction of the new system would save the moshavot from economic catastrophe. Therefore, Hebrew labour was the best hope for keeping the farmers' sons on the moshava. Zimmerman was critical of the Kfar Tavor farmers:

You do not seem to realize that the younger generation is leaving the moshava and that you are responsible. Because you obstinately refuse to adopt the new program which is offered to you, you are unable to make progress. Other moshavot have already accepted the program and have the hope of making progress in the years to come. This is what encourages the younger generation to stay on. You, on the other hand, are destroying everything you have built and driving the younger generation away. ${ }^{38}$

Zimmerman had a similar view of the security issue. Thus,

The disturbances [in 1936] taught us that we need to take control of our lives [...]. We came to understand that we cannot preserve our way of life. Our enemies cannot be allowed to continue living among us. We must reorganize our way of life by introducing Hebrew labour in order to safeguard our lives and possessions. 39

37. November 1929, ibid., protocols 29 and 28.

38. February 1931, ibid., protocol 84 .

39. September 24, 1929, LGFA. 
This was a manipulative, one-dimensional approach: the only problem was the disturbances, the only solution was a change in their way of life. The root of all their problems was the Arabs living on the moshavot. The only solution was to replace Arab labour with Hebrew labour. Other options, such as removing Arab workers from the moshava while still employing them there, or employing the farmers' sons, or the formation of a civil guard, were not even mentioned. In this manner, the security issue became dominant in the debate over hired labour while economic considerations were pushed to the margins.

\section{FAILURE OF THE NEW SYSTEM}

The new system of production, including the introduction of Hebrew labour, was unsuccessful in Kfar Tavor, as it was in most of the moshavot in the Lower Galilee. Only in 1936, the year of the Arab Revolt against British rule, did the harratin leave the moshava, and only as a result of pressure from Jewish security organizations and, to no less an extent, from Arab nationalists. They were for the most part replaced by the farmers' sons, who had left the moshava in the past and now returned. The LGFA ignored the external factors behind this change and instead claimed the credit for itself. This further demonstrates the symbolic importance it attributed to Hebrew labour: "Only five years ago [...] everyone employed Arabs; today the LGFA has managed to eliminate this disgrace in most places." 40 The farmers' sons did not manage to establish themselves on the moshava. They left in 1939 with the end of the Revolt and Arab workers began filtering back into Kfar Tavor.

However, during the decade since 1929, Jewish-Arab relations had been completely transformed. Nationalistic sentiments had become much stronger on both sides. Hiring Arab workers at that point in time put Kfar Tavor beyond the national consensus which opposed Arab labour even more than it favoured Hebrew labour. Against this background, the Galilee Workers Council acted decisively in I94I against Arab labour in Kfar Tavor. A letter to the Committee for the Promotion of Hebrew Production stated that:

Three out of nine [farmers] who supply milk to Tnuva [the monopolistic Jewish dairy] employ Arabs, as do five out of nineteen of those that supply Ezra's dairy in Afula. And this is only counting permanent Arab workers. As for temporary workers, it adds up to hundreds of workdays (all the farmers are guilty here) [...]. Therefore we should not buy milk from them till they stop employing Arabs. ${ }^{4}$

40. 23 February 1936, ibid.

4I. Letter of The Galilee Workers' Council to The Committee for Promotion of Hebrew Production, 3 April I94I, Lavon, series 4, 235 I, fo. Ioro. 
In fact, this was a case of collective punishment based on the idea of collective responsibility among the farmers. Essentially, a collectivist idea, whereby the whole Jewish community in Palestine was considered to be one body, was being imposed onto a capitalistic environment. Several weeks later it was reported that Tnuva had indeed stopped buying milk from Kfar Tavor.

Another powerful institution which joined the fight against Arab labour was Davar, the newspaper of the national labour union, the Histadrut. As for the farmers, they didn't have any organizations fighting for them. Davar first attacked the employment of Arab labour in 1930 during the debate over the new production system: "What makes up this settlement its Jewish landlords [...] or the Arab families who live in its farmyards and cowsheds and who work the fields and vineyards, harvest the grapes, gather the harvest [...]?"42 Ten years later, Davar rejected the farmers' claim that there was a shortage of Jewish workers:

Hebrew workers refuse to come to Kfar Tavor because of the dreadful working conditions offered by the farmers. There are other moshavot in the Lower Galilee which offer conditions that attract Hebrew workers. The farmers of Kfar Tavor prefer cheap [Arab] labour because it has become second nature to them. ${ }^{43}$

In order to illustrate the establishment's intense belief in its position, we return to 1924, during the tobacco boom, when the problem first began to appear. The National Committee itself sent a harshly worded letter to the Kfar Tavor local committee which read as follows: "We do not see why Kfar Tavor should be an exception. It is not possible that the whole country accepts a decision except for Kfar Tavor." After having criticized Kfar Tavor for ignoring a national value, the letter then tried rationally to persuade the farmers:

Besides its value on a national level, there is also economic logic in employing Hebrew labour on the moshavot. Whereas Arab workers take money out of the moshava, Hebrew workers leave it there [...]. Furthermore, these [Arab] families bring contagious diseases into the moshava and Hebrew children pick up bad habits when they play with the poorly brought up foreign Arab children. 44

\section{THE DEFEAT OF THE FARMERS}

Arab workers remained in Kfar Tavor until the establishment of the state of Israel in 1948. In that year, they fled to the Hashemite kingdom and remained there as refugees. However, as we have already seen, their continued presence on the moshava did not indicate a victory for the

42. I3 May 1930, Davar.

43. Iо May I940, ibid.

44. The National Committee to Kfar Tavor, January I924, KTA, series 8-2, file 54 . 
farmers. The moshava had got itself into an impossible situation in which both of its options had significant drawbacks. On the one hand, Hebrew labour was a threat to its economic wellbeing and the future of its sons. The rejection of Hebrew labour, on the other hand, would lead to a serious confrontation with the organizations on which it depended. During the 1940s, farmers became even more frustrated over the issue of labour relations. They felt bitter towards the Hebrew workers who, in their view, were responsible for the tension between them and their organizations. They believed the workers had transformed the question of whether to employ Hebrew labour from a purely professional decision into a struggle for power. Furthermore, they felt that the employment of Hebrew labour had ruined the good relations that had existed with their Arab workers.

The farmers' direct opponent, as we have already seen, was the LGFA. The farmers believed that in supporting Hebrew labour, the LGFA was only serving its own interests, i.e. the desire to curry favour with the national organizations and to maintain exclusive control of the introduction of the new production system. The goals of the LGFA put the farmers in a position from which they could not win. Not only did they themselves lack economic power, their position lacked moral justification since they were in defiance of a national value. Thus, by 1929, they already felt that the die had been cast and that their struggle against the LGFA would only worsen the situation:

If we continue to oppose them by employing Arabs, they will surely consider us to be either traitors or madmen. To whom shall we turn then when we are in trouble $[\ldots]$ ? Hebrew labour will not do us any harm [...]. We will then have the right to request favors for the moshava from the one organization or another." 45

Other farmers hoped the demand to employ Hebrew labour was not really obligatory. Thus, if some farmers wanted to use Arab workers, "should the whole moshava be held responsible?" 46 These words were spoken out of a feeling of surrender rather than victory. The farmers realized that the tables had turned and that they were now dependent on the Hebrew worker, who was favoured over farmers by the various organizations.

Nonetheless, the moshava feared the PJCA even more than the LGFA. It was the PJCA which owned the moshava's lands and assisted the farmers financially. The PJCA craved ending this continuing dependence, and since it believed the new production system would save the moshava, it consenquently supported the employment of Hebrew labour. Thus, the PJCA position was ironically based on economic, rather than moral, considerations and drew its strength from two sources: its own power and the fact that its position conformed to national values. The farmers

45. September 1929, KTA, series 39-3, protocol 24.

46. February I93 I, ibid., protocol 84 . 
understood this all too well, bitterly remarking that: "If you favour nationalism and Hebrew labour, why does the PJCA itself rent out land to the Arabs?". 47

An event which took place in mid-r947 is a good illustration of this relationship. The Kfar Tavor local committee learned that the National Fund, the national settlement organization, intended to buy land clandestinely from private farmers and give it to Beth Keshet, the new kibbutz (collective settlement of Hebrew workers) to the north of the moshava. The shocked committee members wrote the following to the National Fund:

Such an action [...] will destroy the results of our efforts over the years to enlarge the moshava [...]. It appears that the national organizations are giving preference to [collectivist] Beth Keshet [...]. We cannot believe that the National Fund would really give its consent to something like this [...]. Our farmers have been most concerned since learning of this effort. $4^{8}$

The National Fund quickly denied the rumours. However, a letter sent by the local committee to the PJCA shows that the suspicion was in fact wellfounded:

To tell the truth we left the meeting [with you] totally disappointed [...]. It is hard for us to believe that the PJCA has agreed that someone should buy land from our moshava without the knowledge and agreement of the local committee and then transfer this land to another settlement while ours is still struggling to survive. 49

The settlement organizations felt this was perfectly acceptable since in I94 I the farmers had finally "bought" their land following the cancellation of their huge debts by the PJCA. As a result, they felt morally justified in buying up a quarter of Kfar Tavor's land for the establishment of a new settlement. The farmers, in contrast, viewed this as their defeat and as the workers' victory. The organizations had abandoned farmers in favour of the workers who had taken control of the political institutions. Esau had lost his birthright to his younger brother.

\section{CONCLUSION}

The farmers' approach to the issue of labour relations was based on two elements: their financial needs and control over the decision-making process. Over the years they had watched as external bodies appropriated the right to intervene on this issue and to dictate the course of events. This

47. [28 May 1933], LGFA.

48. Kfar Tavor Committee to The National Fund, is July I 947, Lavon, series 4, 235 I, fo. 2 I 68.

49. Kfar Tavor Committee to PJCA, s September I947, Lavon, series 4, 3 I 2 8 I I 4, fo. 47. 
process was accompanied by increasing delegitimization of the farmers' position and a struggle in order to prevent them from hiring workers as they saw fit.

We identified three main characteristics of this process. First, the debate was limited exclusively to Jewish groups. The Arab worker was uninvolved; his voice was unheard. The Jews were well ahead of the Arabs in defining national objectives and in establishing political and organizational frameworks. Thus, there was no organization supporting the harratin. In addition, the dialogue was not between equals. There were three strata of power in this debate: the various organizations, the employers, and the workers. In our particular case, a common denominator existed between the higher and lower levels which led to the weakening of the middle level. Finally, there was a general lack of sensitivity to the needs or values of the other groups. This was especially true in the debate over whether national considerations should take precedence over economic ones in the special circumstances of Kfar Tavor.

Originally, both farmers and workers were considered to be pioneers, but over time the very term "pioneer" underwent a transformation. At first it was used to characterize the role of paving the way for others to follow; it later came to describe a status for which the pioneer served as the normative model. As the political power of the workers increased, the particular values they related to the concept "pioneer", such as Hebrew labour, became increasingly "correct" and finally became absolutely "correct". They gave the term a collective avant-garde image rather than a personal one. Similarly, the issue of Hebrew versus Arab labour was transformed from a personal or local problem into a national and collective one. In order to be part of the national collective, the farmers had to accept the ethos of a mobilized and nation-building society, in which personal interests were subsidiary to collective ones. In their insistence on giving preference to economic considerations, the farmers lost the battle on all fronts. This included their struggle to continue employing Arab labour, the defence of their sons' rights from the encroachment of the Hebrew workers, and, above all, their attempt to preserve their image. The result was pathetic. The farmers became entrenched in their positions and oblivious to the dramatic changes in Jewish-Arab relations over the years. As a result, they were humiliated in the confrontation over the supply of milk in I94I and again in the confrontation over the land given to Beth Keshet in 1947 .

The LGFA supported the positions of the larger and more powerful national organizations, even though they were in direct conflict with the interests of the population they were meant to represent. The LGFA had originally intended to help the farmers but as soon as differences of opinion appeared, it did not hesitate in opposing them vehemently. The LGFA thus trampled on two principles of democracy: the moral 
obligation of a representative to those he represents and the ideal of pluralism.

In the larger context of cultural interaction, two main questions arise: First, does the particular case we have analysed accurately reflect the larger debate over the introduction of Hebrew labour among the Jewish population in Palestine? Shapira ${ }^{\circ}$ studied the internal debates within the Hebrew workers' groups but did not focus on the relations between the national organizations and the unruly periphery. The second question concerns the long-term consequences of the clash between national interests and minority rights, which in our case are those of the farmers. Did lack of empathy remain a characteristic of the political elite and how did this affect the pluralistic nature of the future state of Israel? Further investigation on the local level is needed to clarify this point. In the broader context of social history reflecting frictions and tensions on peripheral level, other questions, reflected in this article, can arise: under what conditions is "a periphery of the periphery" created (in our case: Arab workers)? On the other hand, under what conditions is a peripheral group able to create a leading elite (De Vries raises a similar question in his book)? ${ }^{\text {I }}$

50. Shapira, Futile Struggle.

5. De Vries, Idealism and Bureaucracy. 